\title{
Physical Activity Impairment in Depressed COPD Subjects
}

\author{
Fabiano Di Marco MD PhD, Silvia Terraneo MD, Maria Adelaide Roggi MD, \\ Alice C Repossi MD, Giulia M Pellegrino MD, Anna Veronelli MD, \\ Pierachille Santus MD PhD, Antonio E Pontiroli MD PhD, \\ and Stefano Centanni MD PhD
}

\begin{abstract}
BACKGROUND: Limited exercise tolerance is a cardinal clinical feature in COPD. Depression and COPD share some clinical features, such as reduced physical activity and impaired nutritional status. The aim of the present study was to evaluate maximum and daily physical activities and the nutritional status of COPD patients affected or not by depression. METHODS: In 70 COPD out-patients, daily and maximum physical activities were assessed by multisensor accelerometer armband, 6-min walk test, and cardiopulmonary exercise test. Mental status, metabolic/muscular status, and systemic inflammation were evaluated using the Hospital Anxiety and Depression Scale, by bioelectrical impedance analysis, and with regard to fibrinogen/C-reactive protein, respectively. RESULTS: Depressed subjects (27\% of the sample) showed a similar level of respiratory functional impairment but a higher level of shortness of breath and a worse quality of life compared to non-depressed subjects $(P<.05)$. Specifically, they displayed a physical activity impairment consisting of a reduced number of steps per day, a lower peak of oxygen consumption, an early anaerobic threshold, and a reduced distance in the 6 -min walk test $(P<.05)$ but the same nutritional status compared to non-depressed subjects. In the multivariate analysis, a reduced breathing reserve, obesity, and a higher level of shortness of breath, but not depression, were found to be independent factors associated with a reduced daily number of steps. CONCLUSIONS: Our study found that depressed COPD patients have a reduced daily and maximum exercise capacity compared to non-depressed patients. This further suggests the potential utility of screening for depression in COPD. Key words: depression; COPD; exercise tolerance; dyspnea; nutritional status; CPET. [Respir Care 2014;59(5):726-734. (C) 2014 Daedalus Enterprises]
\end{abstract}

\section{Introduction}

Limited exercise tolerance, related mainly to air-flow obstruction, is a cardinal clinical feature in COPD. Perceived respiratory impairment (dyspnea) is the primary symptom limiting exercise in the majority of patients affected by COPD. ${ }^{1,2}$ Persistent activity-related dyspnea of-

\footnotetext{
Drs Di Marco, Terraneo, Roggi, Repossi, Pellegrino, and Centanni are affiliated with the Respiratory Unit, and Drs Veronelli and Pontiroli are affiliated with the Clinica Medica, San Paolo Hospital, Dipartimento di Scienze della Salute, Università degli Studi di Milano, Milan, Italy. Dr Santus is affiliated with Dipartimento di Scienze della Salute, Pneumologia Riabilitativa, Fondazione Salvatore Maugeri, Istituto Scientifico di Milano Istituto di Ricovero e Cura a Carattere Scientifico, Università degli Studi di Milano, Milan, Italy.
}

The authors have disclosed no conflicts of interest. ten forces patients to adopt a sedentary lifestyle; inactivity, in turn, leads to generalized skeletal muscle deconditioning, further deteriorating the perceived quality of life. Severe activity-related dyspnea is therefore a major contributor to morbidity in COPD and is an independent predictor of poor survival. ${ }^{3}$

The prevalence of depression in COPD patients varies significantly, from 8 to $80 \%$, with mean values around $30 \%$, higher when compared with gender- and age-matched healthy subjects. ${ }^{4-7} \mathrm{~A}$ recent systematic review and meta-

\footnotetext{
Correspondence: Fabiano Di Marco MD PhD, Dipartimento di Scienze della Salute, Università degli Studi di Milano, Via A. di Rudinì 8, 20142 Milan, Italy. E-mail: fabiano.dimarco@unimi.it.
}

DOI: $10.4187 /$ respcare. 02848 
analysis performed by Atlantis et $\mathrm{al}^{8}$ elegantly demonstrated the bidirectional association between COPD and depression, with depression affecting the prognosis of COPD and with COPD increasing the risk of developing depression. Numerous studies found a negative association between depression and an anxious condition and amount of physical activity9-12; moreover, the link is bidirectional since physical activity itself seems to improve depressive symptoms in people affected by depression when compared to no medical intervention. ${ }^{13}$ Hence, the hypothesis that depression plays a role in exercise limitation in COPD patients is not clearly supported, with some studies demonstrating a relationship between depression and reduced exercise capacity in COPD ${ }^{14,15}$ and other studies rejecting it. ${ }^{16-18}$ However, all the of previous studies evaluated exercise capacity with the use of field tests, such as the 6-min walk test (6MWT), which is relatively easy to perform but cannot be considered as sensitive as the cardiopulmonary exercise test (CPET), which defines the level of aerobic fitness on the basis of a comprehensive physiological evaluation. ${ }^{19}$

Malnutrition represents a common and often under-recognized comorbidity affecting COPD patients. Its prevalence ranges from 20 to $40 \%$ in out-patients and up to $70 \%$ in patients with acute respiratory failure or waiting for lung transplantation. ${ }^{20}$ Malnutrition is associated with deterioration of physical performance and development of clinical complications. Survival studies have shown significantly higher mortality rates in underweight patients than in overweight patients affected by COPD. ${ }^{21}$ Depression similarly appears to be linked to poor nutritional status, characterized by poor dietary intake and low serum levels of nutrients. ${ }^{22}$

Therefore, COPD and depression appear likely to play a complementary role in the reduction of physical activity and in nutritional status impairment. The recognition of this dangerous link may be clinically important as a potential target to improve patients' quality of life.

The present study was aimed at evaluating maximum and daily physical activities, nutritional status and body composition, pulmonary function, symptoms, and quality of life of COPD patients according to the presence or absence of depression. The secondary outcome was the study by multivariate analysis of variables related to low daily physical activity.

\section{Methods}

\section{Study Subjects}

Consecutive out-patients attending the Respiratory Unit of San Paolo Hospital (Milan, Italy) aged $>40$ years with a smoking history of $>10$ pack-years and a diagnosis of COPD according to the American Thoracic Society/Euro-

\section{QUICK LOOK}

\section{Current knowledge}

Limited exercise tolerance is a cardinal clinical finding in COPD. Depression and COPD often exist simultaneously and share some clinical features, including reduced physical activity and impaired nutritional status.

\section{What this paper contributes to our knowledge}

Depression coexisting with COPD was associated with a significant reduction in maximum exercise capacity compared to COPD alone. Improving exercise capacity may aid in improving mood profile in COPD patients with depression.

pean Respiratory Society guidelines were recruited. ${ }^{23}$ The study was approved by the local research ethics committee. All patients gave informed written consent.

\section{Functional Symptom Assessment and Comorbidities}

Every subject underwent evaluation of clinical history, including number of exacerbations in the previous year, spirometry, body plethysmography, diffusing capacity of the lung for carbon monoxide, and arterial blood gas analysis. The level of dyspnea was estimated using the Italian version of the Modified Medical Research Council dyspnea scale consisting of 5 statements regarding perceived breathlessness: from grade 1 (I get breathless only with strenuous exercise) to grade 5 (I am too breathless to leave the house). ${ }^{24}$ Comorbidities were evaluated by Charlson index, with higher scores indicating more coexisting conditions. ${ }^{25}$

\section{Physical Activity and Cardiopulmonary Fitness}

Daily physical activity was measured by multisensor armband (SenseWear Pro Armband, BodyMedia, Pittsburgh, Pennsylvania) worn $24 \mathrm{~h}$ a day for 5 days. It incorporates a biaxial accelerometer that records the number of steps per day and physiologic indicators of energy expenditure. We determined the physical activity level by dividing total daily energy expenditure by whole-night sleeping energy expenditure. ${ }^{26}$

CPET to maximum tolerance on an electromagnetically braked cycle ergometer was performed by a progressively increasing (personalized protocol) work rate. Gas exchange was analyzed using a cardiopulmonary metabolic cart (Vmax Spectra, SensorMedics, Yorba Linda, California) at rest $(3 \mathrm{~min})$, during $2 \mathrm{~min}$ of unloaded cycling at 60 rpm, during exercise, and during a final 3-min recovery 
period. Electrocardiogram (12-lead) and cuff blood pressures were recorded. Respiratory gases were sampled continuously from a mouthpiece, and expiratory minute volume, carbon dioxide production, oxygen consumption $\left(\dot{\mathrm{V}}_{\mathrm{O}_{2}}\right)$, respiratory exchange ratio, and other exercise variables were calculated breath-by-breath by computer, interpolated second-by-second, and averaged at 10-s intervals. The anaerobic threshold was derived by V-slope analysis. Oxygen pulse (an index of changes in stroke volume) was determined by standard methods. ${ }^{19}$ Peak $\dot{\mathrm{V}}_{\mathrm{O}_{2}}$ was determined by the highest $\dot{\mathrm{V}}_{\mathrm{O}_{2}}$ achieved during exercise. The breathing reserve was calculated as an absolute value (in L) by the difference between the maximum expiratory minute volume reached during the CPET and the maximum voluntary ventilation (calculated for each patient as $\mathrm{FEV}_{1}$ multiplied by 35$).{ }^{27} \mathrm{~N}$-terminal pro-brain natriuretic peptide was used as a systemic biomarker of heart failure. ${ }^{28}$

The 6MWT was performed indoors along a flat, straight, 30-m walking course supervised by a trained operator according to American Thoracic Society guidelines. ${ }^{29}$ Transcutaneous oxygen saturation and distance walked were recorded.

\section{Metabolic Nutritional Status, Systemic Inflammation, and Anemia}

Body mass index (BMI), fat-free mass index (FFMI), and body fat mass index (BFMI) were measured by bioelectrical impedance analysis using a soft tissue analyzer (Akern Bioresearch, Firenze, Italy). Subjects were considered as having an abnormal nutritional status in the case of nutritional depletion $\left(B M I \leq 21 \mathrm{~kg} / \mathrm{m}^{2}\right.$ or FFMI $\leq 16 \mathrm{~kg} / \mathrm{m}^{2}$ in men and $\leq 15 \mathrm{~kg} / \mathrm{m}^{2}$ in women) ${ }^{30}$ or in the case of obesity (BMI $\geq 30 \mathrm{~kg} / \mathrm{m}^{2}$ or BFMI $\geq 8.2 \mathrm{~kg} / \mathrm{m}^{2}$ in men and $\geq 11.8 \mathrm{~kg} / \mathrm{m}^{2}$ in women). ${ }^{31}$ Subjects underwent blood analysis including cholesterol levels (both high and low density lipoproteins), triglycerides, and albumin. Anemia was defined as a hemoglobin level $<13 \mathrm{~g} / \mathrm{dL}$. ${ }^{32} \mathrm{C}$-reactive protein and fibrinogen served as markers of systemic inflammation.

\section{Depression, Anxiety, and Quality of Life}

Depression and anxiety levels were assessed with the Hospital Anxiety and Depression Scale (HADS), which is self-reported and has been extensively used to screen psychiatric morbidity ${ }^{33}$ in a diverse range of clinical groups, including patients with asthma and COPD. ${ }^{34-37}$ It is composed of 2 parts, the first with 7 questions related to anxiety and the second with 7 questions related to depression. The maximum score for each domain (ie, anxiety and depression) is 21 ; a score of $\geq 8$ in either part is used as a threshold for diagnosing depression and anxiety. ${ }^{33}$

The Italian version of the St George Respiratory Questionnaire comprises 50 items and 76 weighted responses divided into 3 subscales: symptoms, activity, and impact. It was used for the evaluation of quality of life. Scores range from 0 to $100 \%$, with 0 representing the best possible score and $100 \%$ the worst. ${ }^{38}$

\section{Statistical Analysis}

The results are shown as mean \pm SD unless stated otherwise. The sample size was tailored to the multivariate linear regression analysis (shown below) to include at least 6 predictor variables. On the basis of a power calculation, it was estimated that, with an expected prevalence of depression in patients with COPD of $25 \%$, the enrollment of 70 subjects allowed us have an $80 \%$ statistical power and a 5\% significance level of detecting a difference in a 6MWT distance of $60 \mathrm{~m}$. According to the number of enrolled subjects, a Kolmogorov-Smirnov test was performed before the data analysis to examine the data distribution of the overall sample. This test documented that all of the evaluated continuous variables were distributed in a normal way, therefore permitting the use of parametric tests for data management. Continuous variables were compared using Student's $t$ test for paired samples, whereas the Fisher exact test was used for categorical data.

Multivariate linear regression analysis was performed using the number of steps per day as the dependent variable to evaluate if depression itself is an independent factor associated with reduced physical activity. A stepwise approach to model building was applied, including in the model the variable identified by univariate analysis, comparing subjects with a low or high physical activity (using as a cutoff the 50th percentile of the distribution of steps per day).

All tests were 2 -sided, and $P$ values $<.05$ were considered statistically significant. Statistical tests were performed using SPSS19.0 (SPSS, Chicago, Illinois).

\section{Results}

Subject characteristics, pulmonary impairment, history, and quality of life are depicted in Table 1 . Nineteen subjects (27\% of the sample) showed a significant high score of depression.

\section{Features of Depressed Subjects}

A greater percentage of the depressed subjects were women compared to non-depressed subjects, with a concomitant higher score of anxiety. Despite a similar level of respiratory functional impairment in terms of $\mathrm{FEV}_{1}$, inspiratory capacity, diffusing capacity of the lung for carbon monoxide, gas exchange values, and a similar number of comorbidities, they showed a higher level of shortness 
Table 1. Anthropometric, Clinical, and Pulmonary Function Data and Quality of Life

\begin{tabular}{|c|c|c|c|c|}
\hline & $\begin{array}{l}\text { All Subjects } \\
(n=70)\end{array}$ & $\begin{array}{l}\text { Subjects Without Depression } \\
\qquad(n=51)\end{array}$ & $\begin{array}{l}\text { Subjects With Depression } \\
\qquad(n=19)\end{array}$ & $P$ \\
\hline Females, $n(\%)$ & $18(26)$ & $9(18)$ & $9(47)$ & .01 \\
\hline Age, y & $71 \pm 6$ & $71 \pm 7$ & $72 \pm 5$ & .41 \\
\hline Pack-years of smoking, $n$ & $48 \pm 27$ & $48 \pm 27$ & $48 \pm 26$ & .70 \\
\hline Current smokers, $n(\%)$ & $13(18)$ & $9(21)$ & $4(18)$ & .49 \\
\hline Depression HADS & $5 \pm 4$ & $3 \pm 2$ & $10 \pm 3$ & $<.001$ \\
\hline Anxiety HADS & $4.7 \pm 2.9$ & $3.9 \pm 2.8$ & $6.9 \pm 1.8$ & $<.001$ \\
\hline Anxiety, $n(\%)$ & $18(26)$ & $9(18)$ & $9(47)$ & $<.03$ \\
\hline $\mathrm{FEV}_{1}, \%$ & $63 \pm 14$ & $63 \pm 15$ & $61 \pm 11$ & .50 \\
\hline Inspiratory capacity, $\%$ & $75 \pm 21$ & $76 \pm 21$ & $73 \pm 21$ & .60 \\
\hline $\mathrm{D}_{\mathrm{LCO}}, \%$ & $69 \pm 21$ & $70 \pm 23$ & $66 \pm 16$ & .46 \\
\hline $\mathrm{D}_{\mathrm{LCO}} / \mathrm{V}_{\mathrm{A}}, \%$ & $63 \pm 16$ & $62 \pm 19$ & $65 \pm 9$ & .55 \\
\hline Exacerbations previous year, $n$ & $0.73 \pm 0.9$ & $0.8 \pm 1.0$ & $0.5 \pm 0.6$ & .26 \\
\hline Breathlessness, MMRC score & $1.3 \pm 0.8$ & $1.2 \pm 0.8$ & $1.8 \pm 0.6$ & $<.003$ \\
\hline $\mathrm{P}_{\mathrm{aO}_{2}}, \mathrm{~mm} \mathrm{Hg}$ & $75 \pm 8$ & $74 \pm 8$ & $77 \pm 8$ & .18 \\
\hline $\mathrm{P}_{\mathrm{aCO}_{2}}, \mathrm{~mm} \mathrm{Hg}$ & $40 \pm 5$ & $41 \pm 5$ & $39 \pm 3$ & .14 \\
\hline \multicolumn{5}{|l|}{ SGRQ } \\
\hline Total score & $30.4 \pm 13.7$ & $25.2 \pm 11.1$ & $44.3 \pm 9.9$ & $<.001$ \\
\hline Symptoms score & $35.1 \pm 18.5$ & $30.3 \pm 18.6$ & $48.9 \pm 16.0$ & $<.001$ \\
\hline Impact score & $19.1 \pm 14.3$ & $14.3 \pm 11.5$ & $31.9 \pm 13.2$ & $<.001$ \\
\hline Activity score & $47.7 \pm 18.3$ & $41.4 \pm 17.0$ & $64.3 \pm 9.0$ & $<.001$ \\
\hline Charlson index score & $2.0 \pm 1.4$ & $1.9 \pm 1.4$ & $2.3 \pm 1.4$ & .30 \\
\hline \multicolumn{5}{|c|}{$\begin{array}{l}\text { Data are shown as means } \pm \text { SD. Depression and anxiety were defined as a Hospital Anxiety and Depression Scale (HADS) score for depression and anxiety of } \geq 8 \text {. } \\
\mathrm{D}_{\mathrm{LCO}}=\text { diffusing capacity of the lung for carbon monoxide } \\
\mathrm{V}_{\mathrm{A}}=\text { alveolar volume } \\
\text { MMRC = Modified Medical Research Council }\end{array}$} \\
\hline
\end{tabular}

of breath and a statistically significant and clinically relevant lower quality of life score (see Table 1).

No difference was found between depressed and nondepressed subjects in terms of nutritional status, with a similar prevalence of obesity and nutritional depletion in the 2 groups (Table 2). FFMI and BFMI levels were similar in subjects with and without depression. However, depressed subjects showed impaired physical activity and maximum performance as demonstrated by a reduced number of steps per day, a lower peak $\dot{\mathrm{V}}_{\mathrm{O}_{2}}$, an increased anaerobic threshold, and a reduced distance walked in the 6MWT (see Table 2 and Fig. 1). In contrast, depressed subjects showed the same hours of sleep and length of physical activity compared to non-depressed subjects. Finally, we did not find any significant difference between depressed and non-depressed subjects in terms of systemic inflammation evaluated by C-reactive protein and fibrinogen (see Table 2).

\section{Features of Subjects With a Low Daily Physical Activity}

For this univariate analysis, we used the 50th percentile that resulted in a threshold of 6i, 330 steps per day. Sub- jects with a low physical activity ( $<6330$ steps per day) showed a higher score of depression (HADS depression score of $5.9 \pm 4.0$ vs $3.7 \pm 3.8, P=.02$ ), a lower breathing reserve $(11.6 \pm 20.9$ vs $25.3 \pm 30.2 \mathrm{~m}, P=.03)$, a lower inspiratory capacity $(71 \pm 16$ vs $81 \pm 25 \%$ of predicted values, $P=.05$ ), a higher frequency of obesity (34 vs $11 \%, P=.04$ ), a higher level of shortness of breath (Modified Medical Research Council scale score of $1.6 \pm 0.8$ vs $1.1 \pm 0.7, P=.02)$, and a higher number of exacerbations in the previous year $(0.9 \pm 0.9$ vs $0.51 \pm 0.9$, $P=.05)$.

Multivariate linear regression analysis found 3 independent variables with significant effects on the number of steps per day: a reduced breathing reserve, obesity, and a higher level of shortness of breath (Table 3 ).

\section{Discussion}

To the best of our knowledge, this is the first study carried out with COPD patients specifically designed to explore whether depressed patients have a concomitant reduction in physical activity, evaluated comprehensively by CPET, multisensor armband, and 6MWT. Depressed subjects displayed reduced daily and maximum physical 
Table 2. Nutritional Status, Physical Activity, Cardiopulmonary Fitness, and Systemic Inflammation

\begin{tabular}{|c|c|c|c|c|}
\hline & $\begin{array}{l}\text { All Subjects } \\
\quad(n=70)\end{array}$ & $\begin{array}{l}\text { Subjects Without Depression } \\
\qquad(n=51)\end{array}$ & $\begin{array}{l}\text { Subjects With Depression } \\
\qquad(n=19)\end{array}$ & $P$ \\
\hline Body mass index, $\mathrm{kg} / \mathrm{m}^{2}$ & $27.6 \pm 3.9$ & $27.1 \pm 3.9$ & $28.7 \pm 3.8$ & .15 \\
\hline Fat-free mass index, $\mathrm{kg} / \mathrm{m}^{2}$ & $18.6 \pm 1.8$ & $18.5 \pm 1.8$ & $18.8 \pm 1.9$ & .61 \\
\hline Body fat mass index, $\mathrm{kg} / \mathrm{m}^{2}$ & $8.0 \pm 2.6$ & $7.6 \pm 2.6$ & $8.9 \pm 2.6$ & .06 \\
\hline Obesity, $n(\%)$ & $16(23)$ & $10(20)$ & $6(32)$ & .34 \\
\hline Nutritional depletion, $n(\%)$ & $3(4)$ & $3(6)$ & $0(0)$ & .56 \\
\hline Hemoglobin, g/dL & $14.9 \pm 1.5$ & $15.0 \pm 1.6$ & $14.7 \pm 1.4$ & .53 \\
\hline Albumin, g/dL & $4.4 \pm 0.2$ & $4.4 \pm 0.2$ & $4.3 \pm 0.2$ & .12 \\
\hline \multicolumn{5}{|l|}{ Cholesterol } \\
\hline Total, mg/dL & $190 \pm 56$ & $193 \pm 38$ & $183 \pm 25$ & .30 \\
\hline $\mathrm{HDL}, \mathrm{mg} / \mathrm{dL}$ & $55 \pm 10$ & $56 \pm 11$ & $53 \pm 9$ & .39 \\
\hline $\mathrm{LDL}, \mathrm{mg} / \mathrm{dL}$ & $135 \pm 35$ & $137 \pm 39$ & $129 \pm 25$ & .44 \\
\hline Triglycerides, mg/dL & $138 \pm 108$ & $138 \pm 114$ & $139 \pm 57$ & .97 \\
\hline Glucose, mg/dL & $104 \pm 15$ & $102 \pm 15$ & $109 \pm 15$ & .08 \\
\hline Physical activity level & $1.47 \pm 0.15$ & $1.49 \pm 0.16$ & $1.43 \pm 0.10$ & .18 \\
\hline Steps per day & $6,436 \pm 2,595$ & $6,950 \pm 2,431$ & $5,055 \pm 2,576$ & $<.006$ \\
\hline Time $>3$ METs, min/day & $52 \pm 33$ & $56 \pm 32$ & $43 \pm 35$ & .14 \\
\hline Sleep time, min/day & $350 \pm 72$ & $350 \pm 76$ & $351 \pm 52$ & .95 \\
\hline Time lying, min/day & $440 \pm 86$ & $440 \pm 92$ & $442 \pm 69$ & .93 \\
\hline Peak $\dot{\mathrm{V}}_{\mathrm{O}_{2}}, \mathrm{ml} / \mathrm{kg} / \mathrm{min}$ & $19 \pm 5$ & $21 \pm 5$ & $16 \pm 3$ & $<.001$ \\
\hline Anaerobic threshold, $\%$ peak & $72 \pm 19$ & $76 \pm 13$ & $62 \pm 26$ & $<.03$ \\
\hline Breathing reserve, $\mathrm{L}$ & $18 \pm 27$ & $22 \pm 28$ & $9 \pm 19$ & .08 \\
\hline Work maximum, watts & $80 \pm 30$ & $84 \pm 32$ & $70 \pm 20$ & .18 \\
\hline $\mathrm{O}_{2}$ pulse, $\%$ predicted values & $112 \pm 22$ & $113 \pm 20$ & $109 \pm 26$ & .50 \\
\hline NT-proBNP, pg/ml & $152 \pm 201$ & $136 \pm 213$ & $159 \pm 39$ & .26 \\
\hline \multicolumn{5}{|l|}{$6 \mathrm{MWT}$} \\
\hline Distance walked, $\mathrm{m}$ & $378 \pm 93$ & $393 \pm 92$ & $337 \pm 85$ & $<.02$ \\
\hline $\mathrm{S}_{\mathrm{O}_{2}}$ drop, $\%$ & $2.6 \pm 2.3$ & $2.6 \pm 2.4$ & $2.5 \pm 2.2$ & .90 \\
\hline C-reactive protein, $\mathrm{pg} / \mathrm{ml}$ & $9.3 \pm 16.0$ & $10.5 \pm 19$ & $5.8 \pm 3.9$ & .28 \\
\hline Fibrinogen, mg/dL & $372 \pm 68$ & $378 \pm 74$ & $358 \pm 48$ & .30 \\
\hline $\begin{array}{l}\text { Data are shown as mean } \pm \mathrm{SD} \text {. Depressi } \\
\text { to whole-night sleeping energy expenditt } \\
\text { ventilation (calculated as } \mathrm{FEV}_{1} \text { multiplie } \\
\mathrm{HDL}=\text { high density lipoprotein } \\
\mathrm{LDL}=\text { low density lipoprotein } \\
\mathrm{METs}=\text { standard metabolic equivalents } \\
\dot{\mathrm{V}}_{\mathrm{O}_{2}}=\text { oxygen consumption } \\
\mathrm{NT} \text {-proBNP }=\text { N-terminal pro-brain natr } \\
6 \mathrm{MWT}=6 \text {-min walk test } \\
\mathrm{S}_{\mathrm{O}_{2}} \text { drop }=\text { difference between the final }\end{array}$ & $\begin{array}{l}\text { ined as a Hospital An } \\
\text { ng reserve is the diffe }\end{array}$ & $\begin{array}{l}\text { pression Scale score for depression of } \geq \\
\text { en the maximum minute volume reached }\end{array}$ & $\begin{array}{l}\text { activity level is the ratio of total dail } \\
\text { ardiopulmonary exercise test and the }\end{array}$ & $\begin{array}{l}\text { enditure } \\
\text { oluntary }\end{array}$ \\
\hline
\end{tabular}

activities as demonstrated by a reduced number of steps per day, maximum $\dot{\mathrm{V}}_{\mathrm{O}_{2}}$, an increased anaerobic threshold, and a reduced distance walked in the 6MWT despite similar levels of functional and gas exchange impairment compared to non-depressed COPD patients. Moreover, depressed subjects had a higher level of shortness of breath and a clinically important worse quality of life. We did not find any significant difference between depressed and nondepressed subjects in terms of nutritional status, with similar levels of BMI, FFMI, and BFMI cholesterol (both HDL and LDL), triglycerides, and albumin in the 2 groups. Finally, lung function impairment (breathing reserve), nutritional status (obesity), and symptoms (level of dyspnea), but not depression, were independent factors that correlated with the number of steps per day.

The prevalence (27\%) and general features of COPD patients with depression found in our study (more often females, with a perceived worse quality of life and a higher level of shortness of breath) are similar to those of the ECLIPSE study that included $>1,700$ patients. ${ }^{39}$ Moreover, our results correlate with those obtained in a previous study by Al-shair et al, ${ }^{40}$ who, in a cohort of 122 patients with stable COPD, did not find any significant difference between patients with and without depression in terms of muscle wasting, but they found a significant difference in terms of exercise capacity evaluated by the 
A

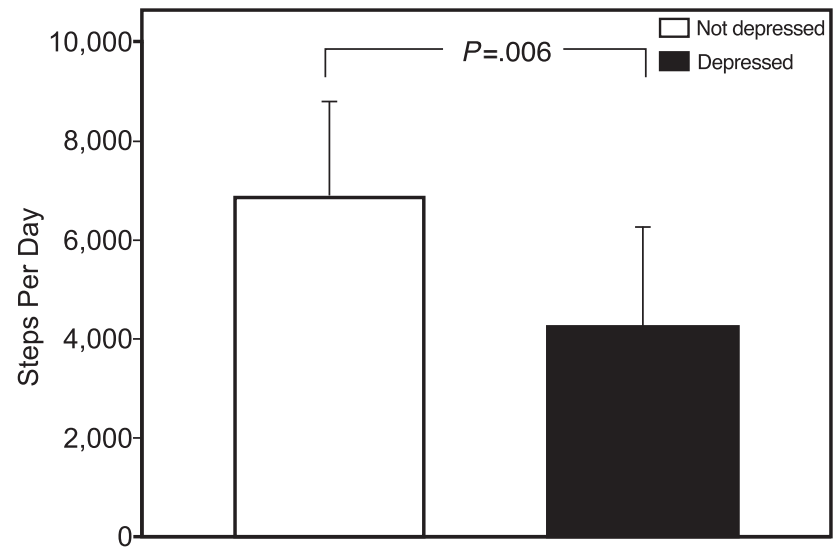

C

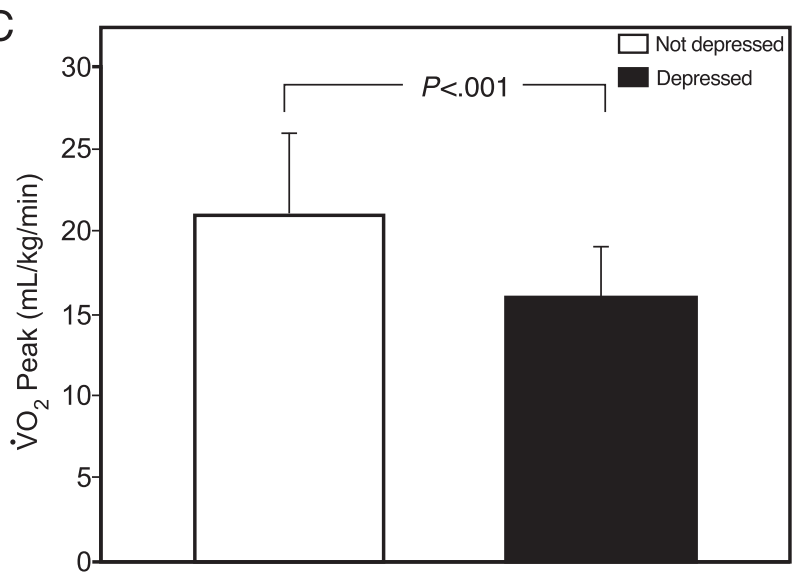

B
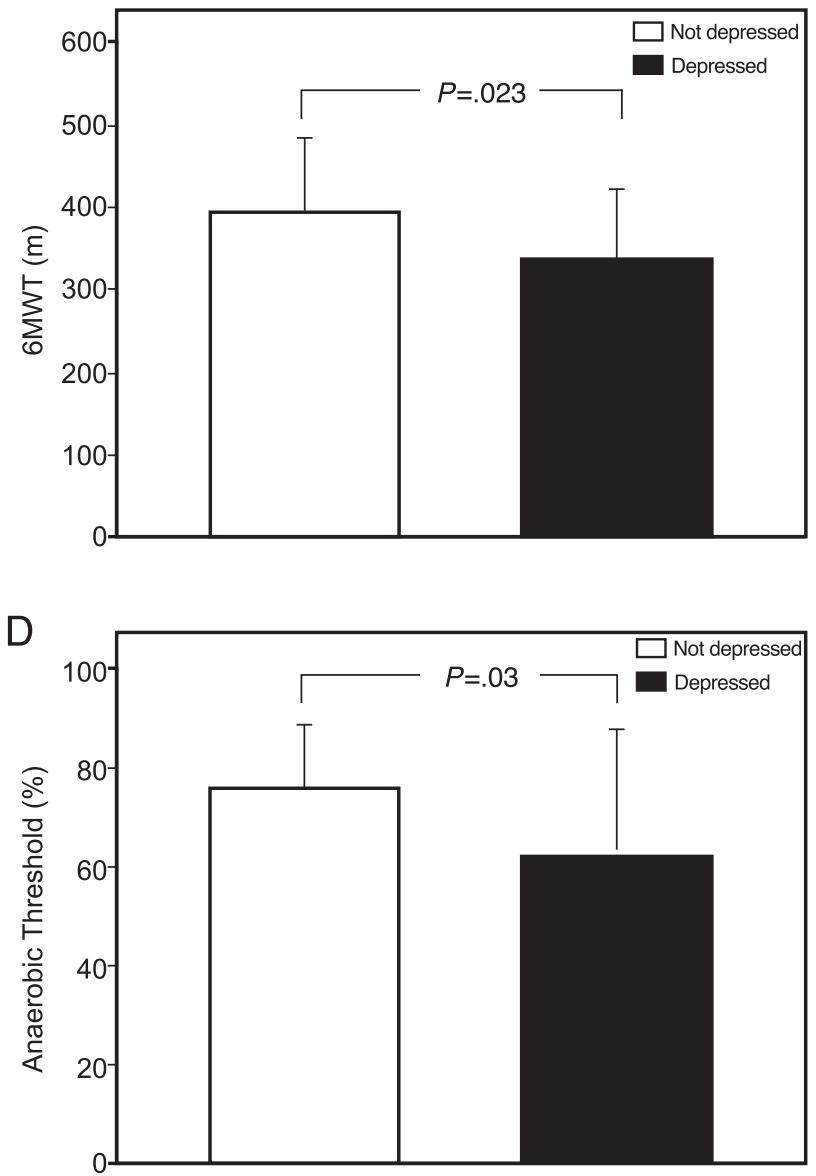

Fig. 1. Differences in exercise capacity between depressed $(n=19)$ and non-depressed $(n=51)$ subjects. A: The number of steps per day recorded by a multisensor armband. B: The distance walked (expressed in meters) during the 6-min walk test (6MWT). C and D: The highest value of oxygen consumption $\left(\dot{\mathrm{V}}_{\mathrm{O}_{2}}\right)$ and the anaerobic threshold, respectively, obtained during the cardiopulmonary exercise test.

Table 3. Predictors of Steps per Day in a Multivariate Linear Regression Analysis

\begin{tabular}{lccc}
\hline \hline \multirow{2}{*}{ Predictive Parameters } & \multicolumn{2}{c}{ Standardized Regression Coefficients } \\
\cline { 2 - 4 } & $\beta$ & $P$ & $\mathrm{r}^{2}$ \\
\hline Depression, HADS score & -0.106 & .84 & 0.16 \\
Breathing reserve, L & 0.406 & $<.001$ & .89 \\
Inspiratory capacity, $\%$ & 0.057 & $<.001$ & 0.16 \\
Obesity & -0.371 & $<.03$ & 0.29 \\
Breathlessness, MMRC score & -0.243 & .83 & 0.35 \\
Exacerbations previous year & -0.023 & & 0.13 \\
& & & \\
Breathing reserve is the difference between the maximum minute volume reached during the cardiopulmonary exercise test and the maximum voluntary ventilation (calculated as FEV ${ }_{1}$ multiplied by \\
35).
\end{tabular}

6MWT. The correlation between depressive symptoms and a poor 6MWT performance was also demonstrated in the ECLIPSE study. ${ }^{15,39}$ However, the 6MWT is a tool that roughly assesses maximum physical activity, and it cannot be used to predict daily nor maximum physical activity. In comparison with the previous ones, our study evaluated these parameters by current accepted standards: CPET and multisensor armband. The recorded information permitted 
a comprehensive evaluation of COPD patients with depression that coupled a reduced daily activity with signs of physical deconditioning, such as a reduced anaerobic threshold. This is particularly dangerous in COPD patients, as the introduction of the vicious circle between shortness of breath, reduced physical activity, and body deconditioning can significantly affect mortality. The early anaerobic threshold we found in depressed patients is particularly interesting since it reflects physical deconditioning, which may be due to and may lead to depression at the same time. It is noteworthy that exercise is of proven efficacy in the improvement of respiratory disability in patients with COPD and seems to improve depressive symptoms in subjects diagnosed with depression compared to no treatment. ${ }^{13}$

In contrast with the ECLIPSE study, we did not find any significant difference between depressed and nondepressed subjects in terms of age and severity of obstruction, expressed by $\mathrm{FEV}_{1}{ }^{39}$ This apparent discrepancy is probably due to the lower number of enrolled subjects in our study; however, the difference found by Hanania et al ${ }^{39}$ in the ECLIPSE study, even if statistically significant, is very small and probably not clinically important since the depressed patients were only 2 years younger, with $\mathrm{FEV}_{1}$ values on average $3 \%$ lower than compared with nondepressed patients.

In accordance with our results, in a cross-sectional study conducted on 70 subjects, Watz et $\mathrm{al}^{41}$ found that depression itself is not an independent factor that correlates with daily physical activity. Interestingly, Watz et $\mathrm{al}^{41}$ found that systemic inflammation and left cardiac dysfunction are associated with reduced physical activity. In our study, even if left ventricular function was not assessed, we did not find any significant correlation between a reduced number of steps per day and the values of $\mathrm{N}$-terminal pro-brain natriuretic peptide, a biomarker of heart failure. In contrast, the discrepancy in terms of systemic inflammation could be due to the features of enrolled subjects. In fact, the group studied by Watz et al ${ }^{41}$ presented a high rate of current smokers (42\%), compared to the $18 \%$ in our study population, and there is a well known role of active smoking itself in both $\mathrm{C}$-reactive protein and fibrinogen. ${ }^{42} \mathrm{Fi}$ nally, the lack of a significant association between depression and systemic inflammation has been confirmed in the large population of the ECLIPSE study, ${ }^{39}$ in which no significant altered levels of fibrinogen and C-reactive protein were detected in depressed subjects.

The correlation observed between physical activity and impairment of the mechanical properties of the lung appears quite convincing since the multivariate analysis found 2 parameters independently correlated to the number of steps per day: a reduced inspiratory capacity and breathing reserve. In our study, obesity was a risk factor for reduced daily activity, as demonstrated previously in the general population. ${ }^{43}$ Similarly, Watz et $\mathrm{al}^{41}$ found that daily ac- tivity is reduced in COPD patients with mild functional impairment and that both BMI and the level of shortness of breath influence the level of physical activity. How do we explain the fact that depression correlates with reduced daily and maximum physical activities but is not an independent predictor of daily activity? This result, in our opinion, highlights the complexity of reduced exercise tolerance in patients with COPD, which is related mainly, as this study found, to lung hyperinflation but also depends on many other factors, including nutritional status and the level of shortness of breath. Depression itself is associated with an increased level of shortness of breath and a worse perceived quality of life, as demonstrated previously.,49 Hence, even if the correlation between depression and impaired physical activity appears consolidated, the reason why COPD patients have limited daily activity is more complex and is mediated by diverse factors, such as the functional impact of the respiratory disease and the perceived level of symptoms and quality of life impairment. Finally, as discussed above, depression can be interpreted as the effect rather than the cause of reduced daily activity.

Our study has limitations that need to be addressed. First, since this is a cross-sectional study, no causality or directionality of the findings can be inferred, a limit common to all of the other studies conducted on the same topic. Moreover, a recent sophisticated systematic review and meta-analysis concluded that there is a bidirectional association between COPD and depression. ${ }^{8}$ Second, we studied a limited number of patients compared to previous studies. This was due to the necessity of carrying out CPET and 5-day multisensor armband evaluation, tests that represent, however, the true originality of our study. Third, we did not investigate appetite and socioeconomic status, parameters that could have helped us in the evaluation of the reason for a potential difference in terms of nutritional status between depressed and non-depressed subjects, which, however, was not found in our study. Finally, depression was evaluated with one simple questionnaire and not with a structured interview or additional questionnaires. HADS has been successfully used in several clinical groups; furthermore, Lavoie et al ${ }^{44}$ confirmed the accuracy of questionnaires by comparing the results obtained with those of a structured interview.

\section{Conclusions}

In this study, we found that depressed COPD patients have a significantly reduced daily and maximum exercise capacity, but not an impaired nutritional status. Specifically, an increased anaerobic threshold suggests the presence of physical deconditioning in these patients and supports the use of therapies aimed at improving exercise capacity that have already demonstrated their utility in COPD and that may also improve mood profile in patients 


\section{Physical Activity Impairment in Depressed COPD Subjects}

with depression. This study suggests the potential utility of screening for depression in patients with COPD.

\section{REFERENCES}

1. O'Donnell DE, Webb KA. The major limitation to exercise performance in COPD is dynamic hyperinflation. J Appl Physiol 2008; 105(2):753-755; discussion 755-757.

2. Palange $P$. The major limitation to exercise performance in COPD is inadequate energy supply to the respiratory and locomotor muscles vs. lower limb muscle dysfunction vs. dynamic hyperinflation. "In medio stat virtus." J Appl Physiol 2008;105(2):762.

3. Ora J, Jensen D, O'Donnell DE. Exertional dyspnea in chronic obstructive pulmonary disease: mechanisms and treatment approaches. Curr Opin Pulm Med 2010;16(2):144-149.

4. Di Marco F, Verga M, Reggente M, Maria Casanova F, Santus P, Blasi F, et al. Anxiety and depression in COPD patients: The roles of gender and disease severity. Respir Med 2006;100(10):1767-1774.

5. Ng TP, Niti M, Tan WC, Cao Z, Ong KC, Eng P. Depressive symptoms and chronic obstructive pulmonary disease: effect on mortality, hospital readmission, symptom burden, functional status, and quality of life. Arch Intern Med 2007;167(1):60-67.

6. van Ede L, Yzermans CJ, Brouwer HJ. Prevalence of depression in patients with chronic obstructive pulmonary disease: a systematic review. Thorax 1999;54(8):688-692.

7. Yohannes AM, Baldwin RC, Connolly MJ. Depression and anxiety in elderly outpatients with chronic obstructive pulmonary disease: prevalence and validation of the BASDEC screening questionnaire. Int J Geriatr Psychiatry 2000;15(12):1090-1096.

8. Atlantis E, Fahey P, Cochrane B, Smith S. Bidirectional associations between clinically relevant depression or anxiety and chronic obstructive pulmonary disease (COPD): a systematic review and metaanalysis. Chest 2013;144(3):766-777.

9. Jonsdottir IH, Rödjer L, Hadzibajramovic E, Börjesson M, Ahlborg G Jr. A prospective study of leisure-time physical activity and mental health in Swedish health care workers and social insurance officers. Prev Med 2010;51(5):373-377.

10. Mikkelsen SS, Tolstrup JS, Flachs EM, Mortensen EL, Schnohr P, Flensborg-Madsen T. A cohort study of leisure time physical activity and depression. Prev Med 2010;51(6):471-475.

11. Teychenne M, Ball K, Salmon J. Physical activity and likelihood of depression in adults: a review. Prev Med 2008;46(5):397-411.

12. Giardino ND, Curtis JL, Andrei AC, Fan VS, Benditt JO, Lyubkin $\mathrm{M}$, et al. Anxiety is associated with diminished exercise performance and quality of life in severe emphysema: a cross-sectional study. Respir Res 2010;11:29.

13. Mead GE, Morley W, Campbell P, Greig CA, McMurdo M, Lawlor DA. Exercise for depression. Cochrane Database Syst Rev 2012(7): CD004366.

14. von Leupoldt A, Taube K, Lehmann K, Fritzsche A, Magnussen H. The impact of anxiety and depression on outcomes of pulmonary rehabilitation in patients with COPD. Chest 2011;140(3):730-736.

15. Spruit MA, Watkins ML, Edwards LD, Vestbo J, Calverley PM, Pinto-Plata V, et al. Determinants of poor 6-min walking distance in patients with COPD: the ECLIPSE cohort. Respir Med 2010;104(6): 849-857.

16. Light RW, Merrill EJ, Despars JA, Gordon GH, Mutalipassi LR. Prevalence of depression and anxiety in patients with COPD. Relationship to functional capacity. Chest 1985;87(1):35-38.

17. Yohannes AM, Roomi J, Baldwin RC, Connolly MJ. Depression in elderly outpatients with disabling chronic obstructive pulmonary disease. Age Ageing 1998;27(2):155-160.
18. Borak J, Chodosowska E, Matuszewski A, Zielinski J. Emotional status does not alter exercise tolerance in patients with chronic obstructive pulmonary disease. Eur Respir J 1998;12(2):370-373.

19. Ferrazza AM, Martolini D, Valli G, Palange P. Cardiopulmonary exercise testing in the functional and prognostic evaluation of patients with pulmonary diseases. Respiration 2009;77(1):3-17.

20. Aniwidyaningsih W, Varraso R, Cano N, Pison C. Impact of nutritional status on body functioning in chronic obstructive pulmonary disease and how to intervene. Curr Opin Clin Nutr Metab Care 2008;11(4):435-442.

21. Raguso CA, Luthy C. Nutritional status in chronic obstructive pulmonary disease: role of hypoxia. Nutrition 2011;27(2):138-143.

22. Sarris J, Schoendorfer N, Kavanagh DJ. Major depressive disorder and nutritional medicine: a review of monotherapies and adjuvant treatments. Nutr Rev 2009;67(3):125-131.

23. Celli BR, MacNee W. Standards for the diagnosis and treatment of patients with COPD: a summary of the ATS/ERS position paper. Eur Respir J 2004;23(6):932-946.

24. Bestall JC, Paul EA, Garrod R, Garnham R, Jones PW, Wedzicha JA. Usefulness of the Medical Research Council (MRC) dyspnoea scale as a measure of disability in patients with chronic obstructive pulmonary disease. Thorax 1999;54(7):581-586.

25. Charlson ME, Pompei P, Ales KL, MacKenzie CR. A new method of classifying prognostic comorbidity in longitudinal studies: development and validation. J Chronic Dis 1987;40(5):373-383

26. Hunter GR, Larson-Meyer DE, Sirikul B, Newcomer BR. Muscle metabolic function and free-living physical activity. J Appl Physiol 2006;101(5):1356-1361.

27. ERS Task Force, Palange P, Ward SA, Carlsen KH, Casaburi R, Gallagher CG, et al. Recommendations on the use of exercise testing in clinical practice. Eur Respir J 2007;29(1):185-209.

28. Rutten FH, Cramer MJ, Zuithoff NP, Lammers JW, Verweij W, Grobbee DE, Hoes, AW. Comparison of B-type natriuretic peptide assays for identifying heart failure in stable elderly patients with a clinical diagnosis of chronic obstructive pulmonary disease. Eur J Heart Fail 2007;9(6-7):651-659.

29. ATS Committee on Proficiency Standards for Clinical Pulmonary Function Laboratories. ATS statement: guidelines for the six-minute walk test. Am J Respir Crit Care Med 2002;166(1):111-117.

30. Vermeeren MA, Creutzberg EC, Schols AM, Postma DS, Pieters WR, Roldaan AC, et al. Prevalence of nutritional depletion in a large out-patient population of patients with COPD. Respir Med 2006; 100(8):1349-1355

31. Kyle UG, Janssens JP, Rochat T, Raguso CA, Pichard C. Body composition in patients with chronic hypercapnic respiratory failure. Respir Med 2006;100(2):244-252.

32. Cote C, Zilberberg MD, Mody SH, Dordelly LJ, Celli B. Haemoglobin level and its clinical impact in a cohort of patients with COPD. Eur Respir J 2007;29(5):923-929.

33. Zigmond AS, Snaith RP. The hospital anxiety and depression scale. Acta Psychiatr Scand 1983;67(6):361-370.

34. Bosley CM, Fosbury JA, Cochrane GM. The psychological factors associated with poor compliance with treatment in asthma. Eur Respir J 1995;8(6):899-904.

35. Nishimura K, Hajiro T, Oga T, Tsukino M, Ikeda A. Health-related quality of life in stable asthma: what are remaining quality of life problems in patients with well-controlled asthma? J Asthma 2004; 41(1):57-65.

36. Cheung G, Patrick C, Sullivan G, Cooray M, Chang CL. Sensitivity and specificity of the Geriatric Anxiety Inventory and the Hospital Anxiety and Depression Scale in the detection of anxiety disorders in older people with chronic obstructive pulmonary disease. Int Psychogeriatr 2012;24(1):128-136. 


\section{Physical Activity ImPairment in Depressed COPD SubJects}

37. Xu W, Collet JP, Shapiro S, Lin Y, Yang T, Platt RW, et al. Independent effect of depression and anxiety on chronic obstructive pulmonary disease exacerbations and hospitalizations. Am J Respir Crit Care Med 2008;178(9):913-920.

38. Carone M, Bertolotti G, Anchisi F. The St George's Respiratory Questionnaire (SGRQ): Italian version. Rasegna Patol App Respir 1999;14:31-37.

39. Hanania NA, Müllerova H, Locantore NW, Vestbo J, Watkins ML, Wouters EF, et al. Determinants of depression in the ECLIPSE chronic obstructive pulmonary disease cohort. Am J Respir Crit Care Med 2011;183(5):604-611.

40. Al-shair K, Dockry R, Mallia-Milanes B, Kolsum U, Singh D, Vestbo J. Depression and its relationship with poor exercise capacity, BODE index and muscle wasting in COPD. Respir Med 2009;103(10):15721579.

41. Watz H, Waschki B, Meyer T, Magnussen H. Physical activity in patients with COPD. Eur Respir J 2009;33(2):262-272.

42. Gan WQ, Man SF, Sin DD. The interactions between cigarette smoking and reduced lung function on systemic inflammation. Chest 2005; 127(2):558-564.

43. Riebe D, Blissmer BJ, Greaney ML, Garber CE, Lees FD, Clark PG. The relationship between obesity, physical activity, and physical function in older adults. J Aging Health 2009;21(8):1159-1178.

44. Lavoie KL, Bacon SL, Barone S, Cartier A, Ditto B, Labrecque M. What is worse for asthma control and quality of life: depressive disorders, anxiety disorders, or both? Chest 2006;130(4):1039-1047. 